East African Medical Journal Vol. 77 No. 11 November 2000

ACCEPTANCE OF HEPATITIS B VACCINE BY WORKERS IN A NIGERIAN TEACHING HOSPITAL

A.O. Fatusi, MBChB, MPH, FWACP, Department of Community Health, O. A. Fatusi, BChD, FMCDS, Department of Oral and Maxillofacial Surgery, A. O. Esimai, MBChB, FMCPH, Department of Community Health, A. A. Onayade, MBBS, MPH, FWACP, Department of Community Health and O. S. Ojo, MBBS, FMCPath, Department of Morbid Anatomy and Forensic Medicine, College of Health Sciences, Obafemi Awolowo University, Ile-Ife, Nigeria.

Request for reprints to: Dr. A. O. Fatusi, Department of Community Health, College of Health Sciences, Obafemi Awolowo University, Ile-Ife, Nigeria.

\title{
ACCEPTANCE OF HEPATITIS B VACCINE BY WORKERS IN A NIGERIAN TEACHING HOSPITAL
}

\section{A.O. FATUSI, O. A. FATUSI, A. O. ESIMAI, A. A. ONAYADE and O. S. OJO}

\begin{abstract}
Objectives: To determine the pattern of vaccine uptake by hospital personnel in a specifically designed pioneer hepatitis $B$ vaccination programme and to highlight major lessons for ensuring success in future programmes.

Design: A review of vaccination and employment records for a forty four-month period and comparative analysis on the basis of professional grouping and work units.

Setting: Obafemi Awolowo University Teaching Hospital Complex, Ile-Ife, Nigeria.

Subjects: A total of 2,548 employees of the teaching hospital that have worked for a minimum of one year on a continuous basis between April 1992 and December 1995.

Interventions: Procurement of recombinant hepatitis B vaccine (Engerix ${ }$, SmithKline Beecham) by the hospital management and provision of the same to all interested employees of the teaching hospital at no cost under a vaccination programme which was conducted on an on-site basis.

Main outcome measures: 'Participation' in the vaccination programme was defined as the uptake of at least one dose of hepatitis $B$ vaccine, and 'compliance' defined as the receipt of the three prescribed doses of the hepatitis $B$ vaccine.

Results: The level of participation in the vaccination programme was high with $91.9 \%$ of the target population of hospital workers receiving at least a dose of the vaccine, while only about half $(53.8 \%)$ of the group complied with receiving the required three doses of the vaccine. In terms of participation, by professional grouping, laboratory workers and nurses recorded the lowest rates $(82.5 \%$ and $84 \%$ respectively), while $100 \%$ participation was recorded in respect of the staff of engineering, medical records, pharmacy and physiotherapy departments. The highest rate of compliance (receipt of three doses) was also found among non-clinical workers (medical record personnel $\mathbf{- 7 6 . 3 \%}$ and engineering staff $\mathbf{- 6 9 . 5 \%}$ ) while the lowest rate was found among nurses $(39.7 \%)$ and doctors $(\mathbf{4 0 . 3 \% )}$

Conclusion: Workers with the highest possibility of knowledge of, and exposure to hepatitis $B$ infection within the hospital setting - doctors, nurses, and laboratory workers - showed the greatest apathy to the vaccination programme. Reasons for this trend demand close examination, and subsequently, identification of specific action that needs to be taken to improve the uptake of the vaccine by the target population, particularly the high-risk groups, in future programmes. Among others, targeting all groups of workers with appropriate education on the infection; active involvement of professional groups in the planning and execution of the vaccination programme; and review of the implementation logistics are some of the key points to note for future programmes.
\end{abstract}

\section{INTRODUCTION}

Hepatitis B virus infection is one of the leading infectious diseases in the world. Globally, at least two billion people are estimated to have the infection, resulting in over 300 million cases of chronic infection and more than two million deaths annually(1). Towards controlling the disease, vaccines - plasma-derived vaccines and later, DNA-recombinant types, have been developed and immunisation has assumed a primary role as a control strategy(2). When properly administered, any of the currently available vaccine is believed to be capable of inducing protection in about $95 \%$ of childhood recipients(2), although some workers had reported the recombinant type to be more effective(3). Despite the fact that sero-conversion rate is known to decrease with age $(4,5)$, the sero-conversion rate in adults, after a course of three injections of the vaccine, is generally high and effective for infection prevention(5-7).

Since contact with body fluids of an infected person, especially infected blood, is one of the principal modes of transmission of the causative virus, health care workers constitute one of the high-risk groups for hepatitis B 
infection $(8,9)$. The prevalence of serological markers of the infection among US health care personnel with frequent contact with blood has been estimated to be in the range of 15 and $30 \%(10)$. The rate would be expected to be higher in the endemic regions of South-east Asia and sub-Saharan Africa. Based on the possibility of high occupational exposure to hepatitis B infection, immunisation of health workers has become a major issue and several countries including Canada(11), the USA(12) and Israel(13) have initiated policies for hepatitis B immunisation for health care workers.

Reports in the last two decades indicated a hepatitis B sero-prevalence rate of between 10 and $40 \%$ among various Nigerian population groups(14-17). Todate, efforts aimed at controlling the infection in Nigeria remain feeble: childhood immunisation is yet to be a reality, and no state policy exists regarding the immunisation of high-risk occupational groups, including health care workers. In spite of the above, the management of a few Nigerian health care institutions, in recognition of the need to safeguard the health of their workers against the infection, had gone ahead to introduce hepatitis B (HB) vaccination programme in their facilities.

The Obafemi Awolowo University Teaching Hospitals Complex is the first Nigerian tertiary health care facility to carry out wide-scale hepatitis B immunisation for her employees. With a bed capacity of five hundred and seventy two beds, it is, arguably, the largest Nigerian hospital to have instituted such a programme todate. The focus in the present paper is to review the rate of participation in the programme and the acceptance of the vaccine among various cadres of hospital workers with the aim of highlighting major lessons that could be of relevance to future programmes.

\section{MATERIALS AND METHODS}

Background to the study and organisation of the immunisation programme: The Obafemi Awolowo University Teaching Hospitals Complex is a public sector tertiary health care institution and affiliated to the College of Health Sciences of the Obafemi Awolowo University, Ile-Ife. The health institution is located in the southwestern part of Nigeria, and serves as the apex referral health care facility for three States Osun, Ondo, and Ekiti States - with a 1991 population of approximately 5.94 million(18). The teaching hospital is a multiunit institution, and comprises of six units located in three communities spread over a geographical area of about 70 kilometres. The six units are: Ife State Hospital (ISH), Ile-Ife; Urban Comprehensive Health Centre (UCHC), Ile-Ife; Dental Hospital (DH), Ile-Ife; Wesley Guild Hospital (WGH), Ilesa; Multipurpose Health Centre (MHC), Ilesa; and Rural Comprehensive Health Centre (RCHC), Imesi-Ile. A shuttle bus system exists, at a highly subsidised price, for transporting workers between various units of the hospital. ISH and WGH provide tertiary/specialist health care services while UCHC and RCHC provide comprehensive primary health care services and the MHC provides, essentially, basic primary health care services. ISH is the administrative headquarters of the hospital, and UCHC is the principal operational base of the institution's preventive medicine and community health activities and programmes. One of such services is provision of routine immunisation to children and pregnant women as part of the National Programme on Immunisation (NPI). As such, facilities for implementing effective immunisation programme, both on static and outreach basis, are readily available at the UCHC. These include various components of the cold chain system and trained manpower.

The period between April 1992 and December 1995 represents the peak of the pioneer hepatitis B vaccination programme in the hospital with high-level publicity and mobilisation across board. Although the HB vaccine continued to be available till recently, the level of attention given to the vaccination exercise has been drastically reduced. The vaccination programme involves the provision of three doses of a yeast derived $\mathrm{HB}$ vaccine (Engerix- ${ }^{\circledR}{ }^{\circledR}$, SmithKline Beecham) using the schedule of 0,6 weeks, and six months with the vaccines being administered into the upper arm. The financial cost of the vaccination programme was entirely borne by the hospital management. The vaccines were offered at each of the units at different dates, with the schedule for each round of the programme pre-announced and well publicised within the institution. However, for workers who might miss their scheduled period for any reason, opportunity for receiving the vaccine was made available at UCHC on a continuous basis. The vaccination team consisted of public health nurses who are primarily based at UCHC. Cold chain system was appropriately maintained during storage, transportation and delivery of the vaccines using the available facilities for the NPI programme. A single vaccination register was maintained for the programme and each worker was required to sign the register at the point and on every occasion of receiving the vaccine. Channels for reporting possible side effects from the vaccine were also made available at UCHC. Overall, a committee consisting of a public health physician, a public health nurse and specialists in laboratory medicine, among others, was constituted to oversee the operation of the programme.

Data collection and analysis: The vaccination register was the source of information regarding the number of doses received by each worker, while the staff nominal roll obtained from the personnel unit of the hospital constituted the source of information about the population of the hospital workers and their units/ occupation. All workers who were in the service of the hospital continuously for a period of at least one year were deemed by the authors to have had ample time and opportunities to receive the complete three doses of the vaccine. As such this was the target population included in the study. Data analysis was carried out using SPSS statistical package for Windows (release 6).

For the purpose of this study, two levels of uptake were defined: 'compliance' was defined as the acceptance of three doses of the vaccine, while 'participation' was defined as the receipt of at least one dose of the vaccine by any member of the study population.

\section{RESULTS}

As Table 1 shows, a total of 1372 workers out of a population of 2548 received the prescribed three doses of vaccines, yielding an overall compliance rate of $53.8 \%$, while the participation rate was $91.8 \%$. A hundred per cent participation rate was recorded among four of the twelve groups/units - engineering unit, medical records department, pharmacists and physiotherapists. The lowest level of participation was recorded among laboratory workers $(82.5 \%)$ and nurses $(84 \%)$. 
Table 1

Uptake of hepatitis B vaccine among different groups of hospital workers

\begin{tabular}{|c|c|c|c|c|c|}
\hline Department & 0 dose & 1 dose & 2 doses & 3 doses & Total \\
\hline Administration & $\begin{array}{r}19 \\
(5.5 \%)\end{array}$ & $\begin{array}{r}33 \\
(9.6 \%)\end{array}$ & $\begin{array}{r}66 \\
(19.1 \%)\end{array}$ & $\begin{array}{r}227 \\
(65.8 \%)\end{array}$ & 345 \\
\hline Catering services & $\begin{array}{r}6 \\
(6.5 \%)\end{array}$ & $\begin{array}{r}13 \\
(14.1 \%)\end{array}$ & $\begin{array}{r}16 \\
(17.4 \%)\end{array}$ & $\begin{array}{r}57 \\
(62.0 \%)\end{array}$ & 92 \\
\hline Doctors & $\begin{array}{r}11 \\
(4.3 \%)\end{array}$ & $\begin{array}{r}48 \\
(18.6 \%)\end{array}$ & $\begin{array}{r}95 \\
(36.8 \%)\end{array}$ & $\begin{array}{r}104 \\
(40.3 \%)\end{array}$ & 258 \\
\hline Engineering & - & $\begin{array}{r}24 \\
(8.7 \%)\end{array}$ & $\begin{array}{r}60 \\
(21.8 \%)\end{array}$ & $\begin{array}{r}191 \\
(69.5 \%)\end{array}$ & 275 \\
\hline $\begin{array}{l}\text { Environmental } \\
\text { sanitation }\end{array}$ & $\begin{array}{r}2 \\
(3.3 \%)\end{array}$ & $\begin{array}{r}8 \\
(13.1 \%)\end{array}$ & $\begin{array}{r}14 \\
23.0 \%)\end{array}$ & $\begin{array}{r}37 \\
(60.7 \%)\end{array}$ & 61 \\
\hline Laboratory service & $\begin{array}{l}\text { es } 21 \\
(17.5 \%)\end{array}$ & $\begin{array}{r}8 \\
(6.7 \%)\end{array}$ & $\begin{array}{r}23 \\
(19.2 \%)\end{array}$ & $\begin{array}{r}68 \\
(56.7 \%)\end{array}$ & 120 \\
\hline Medical records & - & $\begin{array}{r}4 \\
(5.3 \%)\end{array}$ & $\begin{array}{r}14 \\
(18.4 \%)\end{array}$ & $\begin{array}{r}58 \\
(76.3 \%)\end{array}$ & 76 \\
\hline Nurses & $\begin{array}{r}111 \\
(16.0 \%)\end{array}$ & $\begin{array}{r}91 \\
(13.1 \%)\end{array}$ & $\begin{array}{r}221 \\
(31.8 \%)\end{array}$ & $\begin{array}{r}271 \\
(39.1 \%)\end{array}$ & 694 \\
\hline $\begin{array}{l}\text { Orderlies \& other } \\
\text { paramedicals }\end{array}$ & $\begin{array}{r}29 \\
(6.8 \%)\end{array}$ & $\begin{array}{r}32 \\
(7.5 \%)\end{array}$ & $\begin{array}{r}119 \\
(27.9 \%)\end{array}$ & $\begin{array}{r}246 \\
(57.8 \%)\end{array}$ & 426 \\
\hline Pharmacists & - & $\begin{array}{r}3 \\
(8.1 \%)\end{array}$ & $\begin{array}{r}11 \\
(29.7 \%)\end{array}$ & $\begin{array}{r}23 \\
(62.2 \%)\end{array}$ & 37 \\
\hline Physiotherapists & - & - & $\begin{array}{r}4 \\
(30.8 \%)\end{array}$ & $\begin{array}{r}9 \\
(69.2 \%)\end{array}$ & 13 \\
\hline Security unit & $\begin{array}{r}7 \\
(10.6 \%)\end{array}$ & $\begin{array}{r}28 \\
(18.5 \%)\end{array}$ & $\begin{array}{r}35 \\
(23.2 \%)\end{array}$ & $\begin{array}{r}81 \\
(53.6 \%)\end{array}$ & 151 \\
\hline Total & $\begin{array}{r}206 \\
(8.1 \%)\end{array}$ & $\begin{array}{r}292 \\
(11.5 \%)\end{array}$ & $\begin{array}{r}678 \\
(26.6 \%)\end{array}$ & $\begin{array}{r}1372 \\
(53.8 \%)\end{array}$ & 2548 \\
\hline
\end{tabular}

The highest rate of compliance was obtained among workers in the medical record unit $(76.3 \%)$, followed by those in engineering unit $(69.5 \%)$ and physiotherapists $(69.2 \%)$. Doctors and nurses recorded the lowest rate of compliance with figures of $40.3 \%$ and $39.7 \%$ respectively.

\section{DISCUSSION}

The importance of hepatitis B as a major occupational hazard of health care workers has received considerable attention in the literature and the medical world. Without any doubt, immunisation against $\mathrm{HB}$ infection has significant implications for the health and well-being of health care workers and, ultimately, their families and the health system. While it is tempting to assume that health workers will likely show a high level of compliance with regards to beneficial health procedures and programmes, evidence from literature caution otherwise. In the case of hepatitis B immunisation, significant level of nonacceptance has been reported among various groups of healthcare workers and in different settings. The low vaccine acceptance situation has been recorded even in the groups of healthcare workers that have the greatest risk of contact with infected body fluid such as those of the accident and emergency units(19), dental practitioners(20), and surgical residents(21).

In the present study, there was a high level of participation as reflected in the proportion of the target population who took at least one dose of the vaccine
(91.9\%) although compliance with full immunisation dose of three injections spread over six months was much lower $(53.8 \%)$. The result from the present study generally indicates lower uptake of the $\mathrm{HB}$ vaccine by the groups at the greatest risk of infection - doctors, nurse and laboratory workers. Interestingly, these are also the groups of workers that should be more knowledgeable about HB infection and its significance by virtue of their professional training. The trend observed in respect of compliance level in this study is at variance with the pattern observed by CimasHernado et al(22) among Spanish health workers where those with acceptance of the vaccine was greater in those most exposed to the risk of contagion. The overall compliance rate of $53.8 \%$ recorded by us is lower than that reported in healthcare settings by other workers such as Kamolratanakul et al(23) in Thailand (56.9\%), Jepsen and Thomsen(24) in Copenhagen (58.1\%) and Briggs and Thomas in London(25) (65\%) in 1994. The compliance rate of $40.3 \%$ recorded among physicians in our study is also considerably lower than the $80.9 \%$ recorded among Spanish physicians in Aviles county(22), but comparable to the $44 \%$ to $52 \%$ range obtained in different groups of North American surgeons(11).

Failure of the majority of doctors $(59.7 \%)$ and nurses $(60.9 \%)$ to receive the full doses of the vaccine as recorded in this study should be a matter of serious concern to the programme overseers and the hospital management. The reasons for the observed trend in our setting deserve detailed examination and a study is underway in this respect by the authors and other colleagues. A review of the literature and our field observations suggest a number of reasons that could possibly account for poor compliance of doctors and nurses with regards to the HBV vaccination. One major factor is the pressure of work that doctors and nurses face in the course of their daily clinical schedules. Report from the study in Croydon health district of South London(25) supports this opinion. In the face of inadequate staffing and a highly demanding patient load, the average Nigerian doctor and nurse working in urban public sector health facilities face severe work pressure. Other reasons cited in the literature for failure of health workers to receive HB vaccine such as forgetfulness, 'laziness' and 'inertia' $(22,25)$ can also be logically linked with the factor of high pressure of work.

The issue of logistics arrangement surrounding the administration of the vaccine will likely play a significant role in determining to what extent busy health professionals would participate in the vaccination programme(25). While the effort at bringing vaccine to each of the six units of the hospital improved accessibility of each worker to the vaccination team, the long queues occasioned by the limited number of days allotted for vaccination in each unit could have discouraged some people from participating in the programme. Such a situation is likely to disproportionately affect busy groups with patient-related schedules such as doctors and nurses. The availability of hepatitis B vaccine on a constant basis at the UCHC may not fully correct for the situation as there are obvious costs 
involved at the individual level (including transportation and time).

Level of knowledge of the disease and importance of prevention will also affect the rate of uptake of $\mathrm{HB}$ vaccine by various groups of hospital workers. Misconceptions about the pattern of transmission of hepatitis B infection, for example, was reported as a major reason for nonuptake of HB vaccine by some British health workers(25). Interestingly, some studies have shown poor level of knowledge on different aspects of HB infections among doctors in both developed and developing world, for example, among North American surgeons(11) and Nigerian surgical residents(26). The study by Kamolratanakul et al (23) particularly demonstrates the adverse impact of low knowledge on vaccine uptake as the introduction of an educational intervention about the disease significantly increased the rate of acceptance of HB vaccine by Thai health workers from $56.9 \%$ to $77.7 \%$. On the other hand, the fear of side-effects and safety of the vaccine have also been cited by some health workers as their reason for failing to accept HB vaccine $(24,25)$. It is conceivable that the knowledge of side-effects would be greater among doctors and nurses and could have also played a significant role in our study. While the recombinant $\mathrm{HB}$ vaccine is regarded as safe, and adverse reactions to it usually described as being mild in nature, serious reactions such as neurological effects have been documented(27). The possibility that great fear of HB and high expectation of the effectiveness of the vaccine may have increased the participation of the groups with limited knowledge of health problems in the vaccination programme against the background of the results of our study.

The issue of 'personal factors' as relating to the individual's perception of his risk of being infected with the HB virus, lifestyle and attitude to preventive health measures often play a significant role in the utilisation of health services, and have also being mentioned in relation to uptake of HB vaccine(23). The extent to which such personal factors affected our results cannot be determined precisely at present. Nevertheless, these factors also probably serve as a pointer to why educational intervention must be targeted to all the workers as this may result in improvement of relevant perspectives and attitudes. Given the knowledge of our environment, one factor that is unlikely to have played a significant role in uptake of the vaccine is previous exposure and subsequently development of immunity to HB infection(26).

To improve the acceptance of HBV vaccine by health workers in future programmes, it will be important to consider how to address the reasons cited above in the conceptualisation and implementation of such programmes. Indeed, evaluation exercise is a key activity that must be included in future programmes: that is one of the major areas of weakness of the pioneer programme. Hopefully, our on-going follow up study should highlight the relative importance of the role played by various reasons in our local environment. In our opinion one of the ways that workers' acceptance of HB vaccine in future programmes can be improved is to involve the association and leaderships of the relevant professional groups within the hospital setting in the planning and implementation of the programmes. These associations should have specific roles, including organising specific educational activities, mobilising their members to participate in the programme, and deciding together with the vaccination team the best time and suitable logistics for their groups.

One issue that will possibly be raised in the preparation for the future programme is the question of post-vaccination testing to ascertain sero-conversion. If post vaccination testing is to be carried out, the questions of the cost, the timing, and the course of action to be taken in the case of negative result must be adequately considered. As evidenced from the literature, post-vaccination testing within six months of completing the primary series would help to differentiate those who responded to the vaccine from those who did not(28). On the other hand, postvaccination tests undertaken after six months, and especially several years, after completion of the primary series are difficult to interpret as a negative result at that stage may either indicate a primary non-responder or an initial responder whose antibody levels have decreased below detectability but who remains protected against the disease(28). Evidence from the literature indicates that the administration of three additional doses of $\mathrm{HB}$ vaccine in primary non-responders can result in sero-conversion in about $50 \%$ of them(28).

Other issues that may confront future programme organisers in Nigeria and other sub-Saharan African countries may include the following: is there a need for pre-vaccination testing to identify those who really needed to be vaccinated in view of the endemicity of HBV in our environment? Is it even cost-effective to conduct HBV vaccination programme among health workers (or any adult population) in an endemic region? The high cost of $\mathrm{HBV}$ vaccine and need to maximise programme impact in resource-poor environment of the developing countries particularly make these questions pertinent. Our opinion, based on evidences in the literature, is that pre-vaccination testing is not likely to be cost-effective: pre-vaccination testing is generally not cost-effective except where the sero-prevalence of hepatitis B vaccine is greater than $40 \%$ (29). Based on available figures, there is likelihood that the majority of our health workers have not previously contacted HB virus. For example, recent data from a Nigerian tertiary health facility showed a HB seroprevalence rate of $7.7 \%$ among the health workers, which was shown to be lower than that for blood donors in the same environment(30). We consider that the health workers have a right to be protected against $\mathrm{HB}$ virus in view of their increased risk from occupational exposure. To this effect national policies and guidelines advocating and supporting mandatory HBV immunisation need to be put in place. Such regulations should apply to the health workers as well as health professionals-in-training (students). The approach of also vaccinating students has the advantage of easy reach, and ensures that future 
healthcare workers have adequate protection from hepatitis $B$ virus before they enter the period of possible intensive occupational exposure $(31,32)$, The vaccination could be carried out at the point of joining a particular establishment as part of the pre-employment medical procedures (for both workers and students).

Ultimately, the key to controlling the menace of HBV in the Nigerian environment is to offer the vaccine to people during the childhood period. The most cost-effective strategy for mass immunisation of infants is to incorporate hepatitis $\mathrm{B}$ vaccine into the national immunisation programme $(33,34)$. With the present level of $\mathrm{HB}$ prevalence and carrier rate in Nigeria, childhood immunisation against HBV should rightly be considered a priority public health issue.

\section{REFERENCES}

1. Ghedon, Y. WHO strategy for the global elimination of new cases of hepatitis B. Vaccine 1990; 8:129-133.

2. Clemens, C.J., Kane, M., Hu, D.J., and Kim-Farley, R. Hepatitis $\mathrm{B}$ vaccine joins the fight against pandemic disease. Wld Hlth Forum 1990; 11:165-168.

3. Okoth, F. A. Kobayashi, M., Takayanagi, N., Kapttichi D. C., Kaiguri, P. M., and Tukei, P. M. Efficacy of hepatitis B vaccine in a rural community in Muranga, Kenya. East Afr. Med. J. 1994; 71: $250-252$.

4. Cockcroft, A., Soper, P., Install, C., Kennary, Y., Chapman, S., Gooch, C., and Griffiths, P. Antibody response after hepatitis B immunisation in a group of health care workers. Brit. J. Ind. Med. 1990; 47:199-202.

5. Tomasiewicz, K., Modrzewska, R., Lyczak, A., and Rzeswowska, G. Anti-Hbs level after the basic course of vaccination against hepatitis B in health care workers. Przegl. Epidem. 1994; 48: 11-15.

6. Deinhardt, F. Aspects of vaccination against hepatitis B: passiveactive immunisation schedules and vaccination responses in different age groups. Scand. J. Infect. Dis. 1982; 38:17-23S.

7. Fagan, E.A., Tolley, P. and Smith, H.M., et al. Hepatitis B vaccine: immunogenicity and follow-up including two year booster doses in high risk care personnel in a London teaching hospital. J. Med. Virol. 1987; 21:49-56.

8. Hadler, S.C. Hepatitis B virus infection and health care workers. Vaccine 1990; (suppl.) 8; 24-28.

9. Renson, C.E. Hepatitis B: the major infectious occupational hazard. Dent. Update 1994; 21:5-6.

10. Omer, E.E. Clinical significance of markers of hepatitis B. Medicine Digest 1995; 21:10-15.

11. Barie, P.S., Dellinger, E.P., Dougherty, S.H. and Fink, M.P. Assessment of hepatitis B virus immunisation status among North American surgeons. Arch. Surg 1994; 129: 27-31.

12. Hersey, J.C., Martins, L.S. Use of infectious control guidelines by workers in healthcare facilities to prevent occupational transmission of HBV and HIV: results from a national survey. Infect. Control Hosp. Epidem. 1994; 15:243-252.

13. Ginsberg, G. M. and Shouval, D. Cost-benefit analysis of a nation-wide neonatal innoculation programme against hepatitis $\mathrm{B}$ in an area of intermediate endemicity. J. Epidem. Comm. Hlth. 1992; 46:587- 594.
14. Fakunle, Y.M., Abdulrahman, M.B., and Whittle, H.C. Hepatitis B virus infection in children and adults in Northern Nigeria: A preliminary survey. Trans. roy. Soc. trop. Med. Hyg.; 1981; 75:626-629.

15. Abdulsalami, N., Tekena, O.H., Sergei, O.V., Germano, M.R.M., Bernard, B.A., and Vitaly, A.A. Prevalence of Hepatitis B infection markers in representative areas of Nigeria. Int. J. Epidem. 1986; 15:274-276.

16. Bada, A. S., Olatunji, P. O., Adewuyi, J. O., Iseniyi, J. O., and Onile, B. A. Hepatitis B surface antigenaemia in Ilorin, Kwara State, Nigeria. Cent. Afr. J. Med. 1996; 42:139-141.

17. Mutimer DJ, Olomu A, Skidmore S, et. al. Viral hepatitis in Nigerians - sickle cell disease and blood donors. Quart. J. Med. 1994; 87:407-411.

18. National Population Commission. 1991 Population Census of the Federal Republic of Nigeria. Analytical report at the national level. Abuja: National Population Commission. 1998.

19. Dancocks, A., Hewitt, S. Hepatitis B immunisation status of A \& E healthcare workers. Occup. Health. Lond. 1994; 46:20-3.

20. Echavez, M.I., Shaw, F.E., Scarlett, M.I., and Kane, M.A. Hepatitis B vaccine usage among dental practitioners in the United States: an epidemiological survey. J. Publ. Hlth Dent. 1987; 47:182-185

21. Harward, M.P., Kaiser, D.L., and Fedson, D.S. Acceptance of hepatitis B vaccine by medical and surgical residents. J. Gen. Intern Med. 1988; 3:150-155.

22. Cimas-Hernado, J.E., Prieto-Gutierrez, J. and RodriguezRodriguez, J.M. Acceptance of recombinant hepatitis B vaccine by health personnel. Aten. Primaria. 1994; 13:383-385.

23. Kamolratanakul, P., Ungtavorn, P., Israsena, S., and Samulramrung, R. The influence of dissemination of information on the changes of knowledge, attitude and acceptance of hepatitis $B$ vaccination among hospital personnel in Chulalongkorn Hospital. Publ. Hlth 1994; 108:49-53.

24. Jepsen, L.S. and Thomsen, A.C. Attitude of hospital personnel to the risk of hepatitis B and vaccination. A questionnaire study. Ugeskr Laeger 1994; 156: 5514-5518.

25. Briggs, M.J., and Thomas, J. Obstacles to hepatitis B vaccine uptake by health care staff. Publ. Hlth. 1994; 108:137-148.

26. Adebamowo, C. A. and Ajuwon A. The immunisation status and level of knowledge about hepatitis B virus infection among Nigerian surgeons. West Afr. J. Med. 1997; 16:93 - 96.

27. Feely, M. Hepatitis and hepatitis immunisation. J. roy. Soc. Health. 1997; 117: 41-46.

28. Cottone, J. A. and Puttaiah, R. Hepatitis B virus infection. Dent. Clin. N. Amer. 1996; 40:293-307.

29. Kwann-Gett, T.S., Whitaker, R.C., and Kemper, K.J. A costeffectiveness analysis of pre-vaccination testing for hepatitis B in adolescents and pre-adolescents. Arch. Paediat. Adolesc. Med. 1994; 148: 915-920

30. Nwabuisi, C. and Olatunji, P.O. Prevalence of hepatitis B surface antigen among tertiary health workers in Ilorin. Nig. Quart. J. Hosp. Med 1999; 9:95-97.

31. Roush S.W., Hadler, S.C. Shapiro, C.N. and Schatz, G.C. Availability and use of hepatitis B vaccine in laboratory and nursing schools in the United States. Publ. Hlth Rep. 1991; 106:529-535.

32. Rowan, M.S., Carter, A.O. and Walker, V.J. Immunisation policies in Canadian medical schools. Can. Med. Ass. J. 1994; 151: 957961.

33. Fortuin, M. Chotard, J. and Jack, A.D. et. al. Efficacy of hepatitis $B$ vaccine in the Gambian expanded programme on immunisation. Lancet 1993; 341: 1129-1131.

34. Maynard, J. E. Hepatitis B: Towards control and prevention. Afr. Hlth 1993; 15:19-21. 